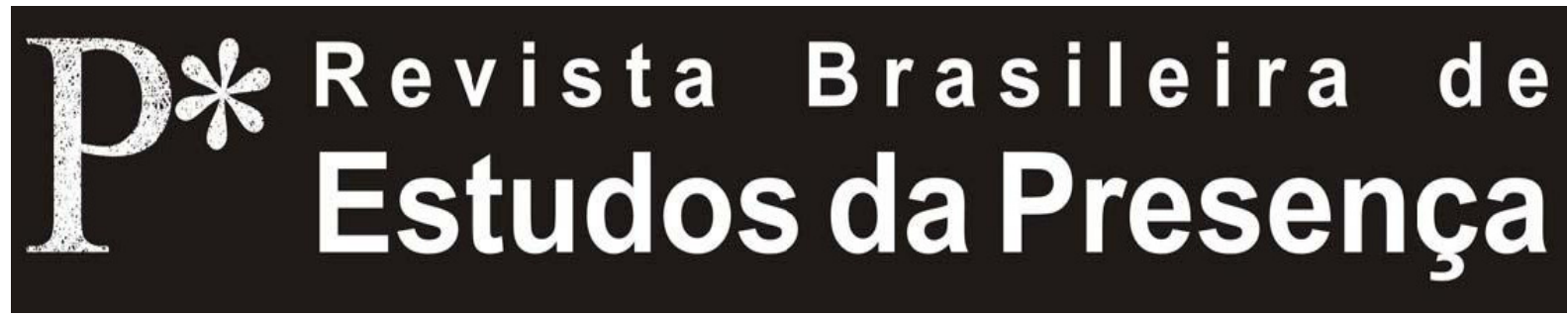

DOI - http://dx.doi.org/10.1590/2237-266036896

ISSN 2237-2660

\title{
Para Além da Tecnologia, a Magia
}

\author{
Lúcia Fernandes Lobato \\ Universidade Federal da Bahia - UFBA, Salvador/BA, Brasil
}

RESUMO - Para Além da Tecnologia, a Magia - $O$ artigo constata que apesar da revolução tecnológica e da espetacularidade do mundo contemporâneo, a magia está para além da tecnologia. A autora se detém na imagem fílmica e argumenta que, desvendar a magia do cinema, significa reconhecer suas estruturas subjetivas disfarçadas na objetividade da tela. Finalmente aponta, no campo atual da produção de imagens, a videodança, fruto da transdisciplinaridade, como um terceiro elemento que aconteceu da fusão da arte com o vídeo, um aparato nascido do avanço tecnológico.

Palavras-chave: Tecnologia. Magia. Transdisciplinaridade. Dança. Vídeo.

ABSTRACT - Beyond Technology, there Stands Magic - This article shows evidence that despite the prominent influences of the technological revolution and the spectacular panoramas on the contemporary world, magic seems to stand beyond technology. To support this hypothesis, the author investigates the images on the cinema, pointing out that to discover magic in a film, for instance, it is necessary to recognize its subjective structures disguised in the objectivity of the screen. Finally, the author indicates that in the field of image production, dance films that are created out of a cross-disciplinary effort are another byproduct of the fusion between art and video, born out of technological advancements. Keywords: Technology. Magic. Cross-Disciplinarity. Dance. Video.

RÉSUMÉ - Au-delà de la Technologie, la Magie - Malgré la révolution technologique et le caractère spectaculaire du monde contemporain, l'auteur de cet article soutient que la magie du spectacle demeure, au-delà de la technologie. Se concentrant sur l'image filmique, il affirme que dévoiler la magie du cinéma revient à reconnaître ses structures subjectives masquées dans l'objectivité de l'écran. Il signale, enfin, que dans le domaine actuel de la production d'images, la vidéodanse devient un troisième élément, fruit de la fusion entre l'art et la vidéo, né du progrès technologique.

Mots-clés: Technologie. Magie. Transdisciplinarité. Danse. Vidéo. 
[...] O passado não pode servir como mestre do presente, e toda tarefa pioneira exige do seu autor um esforço enorme para perder a memória, porque o novo é o ainda não feito ou ainda não codificado. O novo é, de certa forma, o desconhecido e só pode ser conceitualizado com imaginação e não com certezas (Santos, 1988, p. 25).

O mundo contemporâneo convive cada vez mais com o império da tecnologia e da imagem, que inaugurou uma sociedade notoriamente espetacularizada e povoada pela necessidade da publicizaçáo. Vivemos em plena Idade Mídia, com sua proliferação de informações visuais múltiplas, que nos coloca num dilema desconfortante: Como podemos ver tudo?! Seremos capazes de processar tantas informaçóes?

Dentre estes e outros dilemas, nos deparamos também com uma questão. O que significa exatamente a espetacularidade? Segundo Jean Marie Pradier ${ }^{1}$, o significado da palavra espetacular não se reduz ao visual. Refere-se ao conjunto das modalidades perceptivas do homem e sublinha o aspecto global das manifestaçóes expressivas humanas, incluindo as dimensôes somáticas, físicas, cognitivas, emocionais e espirituais. Mas, nem sempre o espetacular foi pensado com essa abrangência atual que lhe dá a Etnocenologia e, por isso, vale refletir sobre a relação das conjunturas históricas com o espetáculo.

A noçáo de espetáculo é quase táo antiga quanto o homem e remonta à antiguidade. Etimologicamente, vem do latim spectaculum, e significava tudo que atraia e prendia o nosso olhar. O espetáculo teve uma função importante na construção da democracia grega como tradutor simbólico dos conflitos da polis. Naquele tempo, era interpretado e reinventado pelo imaginário subjetivo de cada cidadáo, que se identificava com seus conteúdos, pois representavam situaçóes do seu cotidiano político, social e existencial no mundo grego.

O espetáculo, entáo, buscava remeter o indivíduo à condição humana, em grego, o métron e atuava na construção da aletheia, que significava revelar e tornar clara a verdade. Portanto, o espetáculo era um instrumento criado pelo homem grego no sentido de coletivizar seus ideais e sentimentos para dar publicidade às açôes dos seus cidadãos. Platão já reconhecia que o espetáculo não se constituía apenas num divertimento descompromissado, ao contrário, era um poderoso instrumento de transformação da vida social e da política grega.

Esse exemplo da Grécia nos convida a refletir sobre o fenômeno das diferentes formas sociais de espetacularidade que, segundo o professor Armindo Biáo ${ }^{2}$ : 
São tentativas de manipulação da realidade, para "organizar" o caos cotidiano, e permitir a vivência do trágico da vida (a morte inevitável), de caráter extraordinário. São as formas definidoras dos grupos sociais e das relaçóes de poder/contra poder (Bião, 2009, p. 164).

Assim, se observarmos a trajetória do espetáculo, desde a antiguidade à contemporaneidade, percebemos que o homem, independentemente de seu estado civilizatório, buscou registrar seus imaginários e suas performances históricas a partir da construção de imagens. Sem dúvida, criar imagens faz parte da atividade humana e sempre envolveu um elemento mágico.

Não há dúvida que a magia é um elemento intrínseco da arte que, por sua vez, através dos tempos assimilou os diferentes avanços das técnicas para aperfeiçoar suas criaçóes. Mas, só com o aparecimento do cinema podemos falar do surgimento de um significativo aparato tecnológico para a produção de uma virtualidade imagética. $\mathrm{E}$, desde esse acontecimento, se impôs para nós a difícil tarefa de compreender as relaçôes entre a tecnologia e seus efeitos surpreendentes nos produtos da criação artística.

Já estávamos acostumados a lidar com a relação conflituosa entre técnica versus processos artísticos. Porém, a revolução tecnológica que vivemos tornou a questão muito mais complexa. A pergunta que hoje se coloca é se a tecnologia passou a ser um fator fundamental e imprescindível para o sucesso da realizaçáo do artista. Por conta dessa questão, houve e ainda há muita reação em reconhecer e incluir, por exemplo, o cinema como uma arte. E, a bem da verdade, isso ainda não está totalmente resolvido, sendo que os menos radicais lhe concederam o título de a sétima arte. Mas este é um conflito inócuo, porque tanto a arte como o cinema nos atraem para uma mesma questão: o irresistível desafio de decifrar o enigma da magia para além da tecnologia.

Nesse sentido, meu olhar de artista entusiasmada pelos processos da criação percebe que, desde as engenhosas aparelhagens inventadas pelos irmãos Lumière até as sofisticadas tecnologias contemporâneas, nada superou para o espectador do cinema a simples magia contida em suas imagens e que provoca o encantamento. Seja com recursos mais artesanais ou com o fantástico aperfeiçoamento computacional, o que é recorrente nos sucessos da história do cinema é o fascínio de suas revelaçóes em forma de imagem. 
No entanto:

Este fenômeno espantoso retém pouco a atenção dos historiadores do cinema, os quais encaram, segundo uma finalidade ingênua, o período de gênese do cinema como um período de aprendizagem, durante o qual se elaboram uma linguagem e os meios, por assim dizer, predestinados à formação da "sétima arte". Ninguém se espanta que o cinematógrafo tivesse sido, desde o início, radicalmente desviado dos seus fins aparentes, técnicos ou científicos, que o espetáculo tivesse tomado posse dele transformando-o em cinema (Morin, 1997, p. 25).

A advertência do autor nos induz a reafirmar que foi o impulso pelo espetacular que moveu os primeiros cineastas, e não apenas seu desejo de dominar ou superar os artifícios técnicos disponíveis para a revelação da cena. Nessa lógica, podemos perceber que quando os Lumière tornavam espetaculares as simples cenas do cotidiano como, por exemplo, a saída dos operários ao final de sua jornada de trabalho na fábrica, queriam não apenas registrar, mas surpreender os espectadores com uma espécie de espelho no qual poderiam reconhecer a si próprios e suas realidades de forma compartilhada. Isso quer dizer que:

O que atraiu as primeiras multidóes não foi a saída de uma fábrica, ou um comboio a entrar numa estação (bastaria ir até à estação ou até a fábrica), mas uma imagem do comboio, uma imagem da saída da fábrica. Não era pelo real, mas pela imagem do real, que a multidáo se comprimia às portas do Salon Indien (Morin, 1997, p. 33).

Provavelmente o fio da meada para compreender a magia do cinema para além da tecnologia está em reconhecer a realização de sua poética, que não objetiva simplesmente a vida, mas sim promove o encantamento a partir das imagens da vida. E essa observação nos reportará ao espetáculo grego, que encantava o cidadáo por lhe colocar no centro da representação e das expressóes refletidas de suas próprias problemáticas existenciais e políticas vividas na polis através de uma espécie de imagem irreal, mas que se apresentava como espelho do real. Estamos tratando dos poderes gerados pelos virtuais.

Assim, entendo que compreender o fenômeno da magia nos remete às questôes relativas à produção dos virtuais. Essas imagens, apesar de não terem concretude, promovem realidades que provocam, por sua vez, emoçóes e sentimentos, estes sim concretos e reais. Nesse sentido, é preciso compreender que apesar da construção da imagem ser uma realidade vivenciada, resulta numa ausência real que 
não se enquadra na oposição binária entre presença versus ausência. Trata-se de uma presença-ausência que ganha autonomia e passa a ter poderes para realizar o sonho do homem de se eternizar. Assim, ele pode viver a ilusão de vencer até a morte, eis que, nesse caso, a problemática da morte é apropriada pela vida.

Sobre a relação entre a realidade e o sonho, o professor Paes Loureiro $^{3}$ nos diz que:

O real nos coloca diante da objetividade prática de viver. $\mathrm{O}$ imaginário nos garante as aventuras de sonhar. Sonhamos antes de conhecer. Imaginamos antes de constatar. Nosso devaneio é incansável, interfere na realidade, poetizando a relação pregnante com essa realidade, o que faz com que, tantas vezes, o imaginário seja mais real do que real. O imaginário confere ao real sentido. Inclusive o do próprio real. Não há real náo imaginado (Loureiro, 2007, p. 17).

A imagem fílmica nos leva a essa possibilidade do devaneio, de sonhar acordado, permitindo-nos inclusive façanhas impossíveis na vida real. $\mathrm{O}$ homem pode projetar-se sobre todas as coisas e também sobre todos os tempos passados, presentes e até futuros. A possibilidade desse mundo irreal/real cria uma imagem gigantesca da vida e da sobrevida. Nesse sentido, para Morin, a magia provocada pelo cinema nada mais é do que uma alienaçáo reificadora dos fenômenos subjetivos. Segundo ele "[...] tudo o que é imagem tende, em certo sentido, a tornar-se afetivo, e tudo o que é afetivo tende a tornar-se mágico" (Morin, 1997, p. 50).

A imagem, ao reproduzir e exteriorizar um indivíduo, the causa estranhamento e promove o inconfessável porque o desvela! De certa forma, é uma espécie de revelação de nossa autotraição. É perturbador quando a imagem nos apresenta a simultaneidade em conflito de nossa semelhança e diferença. Esse é um dos impactos que a imagem fílmica provoca. Surpreende essa possibilidade de um mundo duplicado, que tenta absorver a vida real projetando-a como um espetáculo aparentemente mágico.

São essas e outras instigantes e curiosas questóes que me levam a investigar os processos que ressaltam a magia enquanto um fenômeno da ilusáo. A magia acontece quando nossos estados subjetivos se desligam de nós para tomarem corpo no mundo. Um filme, apesar de sua objetividade em formas reais, é sempre irreal para o espectador. Ele sabe que a imagem que está vendo não é palpável, mas fruto de sua percepção estética que, em última instância, felizmente impede que o filme se torne tấo sério e insólito quanto o real. Isso significa 
que o universo mágico e lúdico, então, é simplesmente uma visão subjetiva que se acredita real e objetiva, mas que dignifica a existência da vida humana.

Esse fenômeno me leva a crer que a magia nada mais é do que a concretização da subjetividade. Então desvendar a magia do cinema significa reconhecer suas estruturas subjetivas disfarçadas e fixadas na imagem da tela. Assim sendo, entendo que esse resultado em tela se diferencia do espetáculo apenas como resultado da imagem, mas náo como gênese de criaçáo que, enquanto processo, pertence ao mesmo universo mágico do imaginário artístico.

II

Cada vez que as condições gerais de realização da vida sobre a terra se modificam, ou a interpretação de fatos particulares concernentes à existência do homem e das coisas conhece a evolução importante, todas as disciplinas científicas ficam obrigadas a realinhar-se para poder exprimir, em termos de presente e não mais de passado, aquela parcela de realidade total que lhes cabe explicar. Vivemos, agora, uma dessas fases onde a significação das coisas experimenta uma mudança praticamente revolucionária (Santos, 1988, p. 18).

Todo o argumento até então desenvolvido me transportou a outro fenômeno introduzido pela contemporaneidade e apontado por Edgar Morin como a transdisciplinaridade. As fronteiras, antes tão preservadas nos diversos campos do conhecimento, se dissolveram, dando lugar ao surgimento de campos híbridos do saber que, por sua vez, possibilitaram o aparecimento de novas disciplinas oriundas de fusóes.

Esse processo teve origem com a interdisciplinaridade que abriu o diálogo das ciências afins. Mas isso logo foi ultrapassado, pois a agilidade do pensamento e as solicitaçóes da aceleraçáo dos acontecimentos exigiram respostas mais complexas que só a transdisciplinaridade poderia dar conta.

Esse fenômeno atual aproximou, no campo da produção de imagens, a dança do vídeo, inaugurando o que se convencionou chamar de videodança. Fruto da transdisciplinaridade, a videodança se constitui em um terceiro elemento que aconteceu da fusão da arte da dança com a tecnologia e com o vídeo. Este último, um aparato nascido do avanço tecnológico da produção da imagem fílmica. Porém, mais do que uma fusão, me permito falar de disjunção, pois é preciso que esses dois campos do saber consigam se comunicar entre 
si, sem simplificaçôes e/ou reducionismos. É importante conceber a possibilidade de realização de uma unidade na qual estáo preservadas as multiplicidades que as constituíram. Trata-se de identificar o que une a dança ao vídeo, ao invés de reconhecer o que os separa.

Isso significa que aquele que pretende se tornar um profissional da videodança deverá também ser esse sujeito híbrido, que tenha o conhecimento da dança e do vídeo fundidos num só profissional/ artista. Não é suficiente que ele seja um excelente técnico capaz de roteiros perfeitos, planos surpreendentes, efeitos cinematográficos incríveis e inovadores. Mas ele deverá, concomitantemente, ter uma experiência profunda da dança, conhecer, identificar e distinguir seus procedimentos técnicos, seus processos de criação, suas estéticas em conflito e seus atuais desafios.

Considero que o maior desafio da dança hoje é provocar o interesse e integrar o espectador no jogo das diferenças proporcionado por artistas e coreógrafos. É preciso despertar para os distintos processos de sua criação, nas descobertas de suas proposiçóes em conflito e suas repercussóes. A dança não pode ser apenas um affair dos pesquisadores e curiosos das tecnologias da construçáo da cena. Precisa seduzir o espectador para o simples prazer do dançar.

A dança, como qualquer outro saber, vive suas transformaçóes e está tentando absorver e responder às atuais solicitaçóes do mundo contemporâneo. Entre elas, ressalto as novas configuraçôes e pesquisas sobre a relação corpo e movimento. A dança busca superar o dualismo cartesiano que separa a mente do corpo. Ela quer compreender a dinâmica do pensar/fazer do corpo dançarino que náo se sujeita mais às imposições rígidas das técnicas e dos padrôes estéticos. Esse corpo está mais preocupado com seu trajeto e com as possibilidades de alcançar a imagem/revelação/espelho de sua escritura e dos seus mistérios encarnados.

A magia do mover passou a falar a despeito do dançarino. Esse mover resignifica sua sensibilidade, fisicalidade, história de vida, herança cultural e genética que, somadas ao seu preparo profissional e artístico, resultarão num discurso corporal singular e intransferível que promoverá a dança. Nesse caso, ao invés de investir na aplicação de técnicas de dança consagradas, o caminho é pensar metodologias independentes dos sistemas fechados. Segundo Maffesoli (1988, p. 16), "É possível que cada um, em função das situaçóes que tenha de viver ou analisar, elabore, partindo de delineamentos propostos, sua própria construção". 
Nesse sentido, o modelo clássico e o padrão moderno não repercutem mais, pois já se transformaram em memória. Dizem respeito a habilitar corporalmente o dançarino para a execuçáo de repertórios de técnicas e expressividades definidas por uma estética pré-concebida da qual se apropria um determinado coreógrafo em um determinado momento. Seu valor enquanto revelador da História é inegável, mas não vai interferir mais no mundo atual.

A contemporaneidade rompeu com a precisão e instaurou o momento do risco, da fragmentação. Vivemos num estado de incoerência coerente. $\mathrm{O}$ virtuosismo baseado na perfeição e na aproximação máxima ao padrão estético estabelecido caiu por terra. $\mathrm{O}$ novo desafio náo está em aparecer ao outro, mas no reconhecimento de si próprio ao se apresentar para o outro.

Para tanto, o dançarino está à procura de sua corpo-bio-grafia ${ }^{4}$, por mim proposta como uma perspectiva desconstrucionista e transdisciplinar em dança que, a partir do afrouxamento das singularidades encarnadas, busca alcançar a autonomia do corpo enquanto unidade expressiva do indivíduo. Essa proposta, ao invés de investigar como a personalidade molda o movimento, busca, no caminho inverso, descobrir como o movimento pode construir as identificaçóes do indivíduo, tornando-o capaz de se expressar e se inscrever com propriedade no ambiente e na sociedade.

A busca por essa unidade orgânica na perspectiva corpo-biográfica me levou a relacionar algumas categorias corporais básicas da estrutura física de cada sujeito. Essas categorias, se acionadas, potencializarão sua confiança e darão o suporte para o seu mover único e intransferível.

A primeira são os pontos de apoio, as partes que sustentam o corpo no chão ou em qualquer outro contato. A cada nova posição ocorre uma mudança. O reconhecimento de novos pontos de apoio trará maior segurança e confiabilidade para mover porque sempre será possível evitar o desmoronamento.

A segunda é o eixo corporal, que implica reconhecer a coluna vertebral e suas possibilidades articulares. Perceber a coluna e sua função estruturante, bem como seu potencial de flexibilidade, vai despertar e incentivar o indivíduo a encontrar-se tanto no estado de equilíbrio como no desequilíbrio. Equilíbrio e desequilíbrio são sustentáveis a partir de acionados os respectivos apoios e representa, na experiência cinestésica, a condição do próprio viver compensado ao nível social e político. 
A terceira é a articulação. Aprender a dissociar as maiores e menores partes do corpo capacita o ser articulável. Aquele que pode dobrar e desdobrar, desenvolver, encolher ou expandir. Articular é saber dividir-se em diferentes partes sem perder a unidade.

A quarta consiste em reconhecer o centro de energia geradora da força do corpo. Segundo Klauss Vianna:

O corpo humano é uma síntese do Universo. Acionado o centro de energia, qualquer movimento executado estará dialogando com as forças da natureza cósmica como o tempo, o espaço e a energia vital. [...] Apesar de todo o conhecimento acumulado a seu respeito, o corpo humano ainda não foi completamente explorado e talvez nunca cheguemos a conclusốes definitivas sobre suas potencialidades. De qualquer forma, sua existência revela a presença de algo cuja dimensão transcende a sua própria materialidade: aquilo que comumente chamamos de energia vital (Vianna, 1990, p. 105).

Finalmente, respirar é oxigenar o interior do corpo alimentando as células, conectando o exterior com o interior do sujeito. Concentrar e ampliar o trajeto do ar na respiração renova e reanima órgãos e sensaçôes, dá a dimensão do viver expandido.

Considero que a proposta de uma corpo-bio-grafia respeita as leis da natureza porque reconhece que elas são inerentes ao próprio corpo e indica que, ao nos tornamos natureza, realizamos uma escritura harmônica de pertencimento.

O corpo contemporâneo quer a dignidade de se movimentar por conta própria. Quer se reconhecer portador de memória, cultura e saberes. Quer se libertar da homogeneizaçáo para reconhecer e ressaltar suas diferenças.

É possível identificar atualmente um movimento desconstrutivista capaz de apresentar um discurso corporal que, assumido coreograficamente, pode traduzir e ressaltar as diversidades e diferenças na Dança ao invés de homogeneizá-la em padróes universalistas. O propósito é encontrar as características desse movimento que, a partir de sua (com)posição e/ou (de)composiçáo, apresenta uma espécie de narrativas corporais que podem ser compreendidas como as Escrituras em Dança. Isso pressupóe o entendimento de que os textos podem se apresentar tanto no formato escrito, quanto oral, corporal e principalmente imagético.

Muitas são as transformações que vêm acontecendo no ambiente da dança tanto no fazer artístico, como nas suas ambiçóes enquanto área de conhecimento. Esse processo exige que por trás da lente da 
câmera, que tenta o registro do movimento, esteja um artista/criador/ híbrido na tentativa audaciosa da videodança.

Sabemos hoje que a ciência não se desenvolveu pelo acúmulo de conhecimento, mas sim pela capacidade do cientista de transformar os próprios princípios que os organizam. Por isso esse profissional que surge deve estar capacitado para colocar seu olhar sensível a serviço do seu próprio subjetivo no momento de captar aquela imagem/movimento tão plena de sua emoção que será capaz de surpreender tanto o dançarino como também o olhar do mais desatento espectador.

Este artista, porque borra as fronteiras dos saberes e dos fazeres, poderá criar representaçôes simbólicas emergentes que possibilitarão novos traçados e novos sistemas de imagens e percepções.

Nessa direçáo, aponto que no Brasil já existem alguns Centros de Estudos Acadêmicos conceituados que se dedicam a pesquisa em videodança. Esses Centros, inclusive, já incorporam em seus currículos disciplinas com conteúdos específicos para essa área de estudo. Cito apenas aqueles com os quais mantenho maior relação e conhecimento, como por exemplo, o LAPAC, na Escola de Dança da Universidade Federal da Bahia, e o PECDAN, no Departamento de Artes Corporais da Escola de Educaçáo Física e Desporto da Universidade Federal do Rio de Janeiro (UFRJ), ambos com pesquisas e disciplinas inauguradas especificamente para essa linha de investigaçáo. Este último, o Departamento de Artes Corporais da UFRJ, por exemplo, vem de realizar concurso público para professor na especificidade de videodança para atuar como docente na graduaçáo daquela unidade acadêmica.

No entanto, apesar do ritual iniciático necessário para a partida desse novo saber já estar em curso, eu considero que esse é um campo de pesquisa que está apenas começando e por isso mesmo é muito instigante. Os profissionais de ambos os saberes já se reconhecem, trocam os resultados de suas experiências e transitam com satisfação suas investigaçôes, criando redes em seus diferentes territórios de domínio. Atuam no lugar do entre, que náo deve ser confundido como um espaço vazio ou, ainda, um não-lugar. Muito pelo contrário, é um espaço pleno onde acontece a possibilidade da absorção para o surgimento do novo.

Agora, habitando este lugar, cabe aos artistas/híbridos, que despretensiosamente vão chegando, apresentar um investimento apropriador suficientemente sedutor para realizar a fusão da dança com 
o vídeo e dar substância inovadora a este conhecimento nascituro. Minha recomendação para esses profissionais se inspira em Morin:

[...] estamos na altura de propor um modo de modelizaçáo (mais do que um modelo) de um fenômeno reconhecido complexo, considerando-o a priori - a imagem da inteligência que o constrói - como uma organização ativa, organizante [ou computante e sobretudo informante (ou como registro)]. Um sistema complexo é inteligente a partir do reconhecimento de sua (ou suas) função (óes) de memorização-computação, que não revelam tanto as determinaçôes de seus comportamentos necessários, mas sobretudo as condiçóes de seus comportamentos possíveis e, portanto, antecipáveis, no fio irreversível do tempo de sua ação e do registro (Morin, 2000, p. 247).

A videodança, fusão a que me refiro, no entanto, só acontecerá quando concretizada como um terceiro elemento inaugurado além da dança e além do vídeo e que será capaz da incorporação dos elementos da criação com os elementos da tecnologia em prol de uma especificidade: a videodança.

Para tanto, esse novo saber não pode se esquivar da ousadia, não pode deixar de assumir as situaçóes que envolvem o risco. Deve saber jogar e não ter compromisso com a ordem do possível, nem apostar na previsibilidade. Deve ter entusiasmo!

O entusiasmo sempre foi considerado pelas hierarquias do poder, desde Platão, como uma atividade perigosa e subversiva porque promove a autonomia. A este respeito, Fernando Muniz, em seu artigo intitulado Platáo contra a Arte, da Coletânea Os Filósofos e a Arte, organizada por Rafael Haddock-Lobo, observa que:

Quando canta, Íon está possuído pelas Medusas, está entusiasmado, éntheos. Éntheos significa literalmente "ter um deus dentro", e o substantivo enthusiasmós, o estado resultante desta intervenção psíquica (2010, p. 20).

Assim, o entusiasmo nos aproxima dos Deuses e nos permite o impossível de tornarmo-nos o acontecimento de nós mesmos realizando nossa imaginação no ato da criação. Nos domínios do éntheos chegamos à outra dimensão e nos surpreendemos. É ele que move a criação, as descobertas e, portanto, a possibilidade do acontecimento de novos saberes.

Que seja bem vinda a videodança! Esse momento está bem próximo e certamente, para além da tecnologia, vencerá a magia! 


\section{Notas}

${ }^{1}$ Jean-Marie Pradier é membro permanente da Escola Internacional de Antropologia Teatral - dirigida por Eugênio Barba -, e professor da Université Paris 8 e autor do Manifesto da Etnocenologia publicado em 1955 em Théatre-Public 123, maio/jun. p 46-48.

${ }^{2}$ Armindo Jorge de Carvalho Bião é pesquisador do CNPq e Professor Dr. Titular da Universidade Federal da Bahia. Dirige o Grupo Interdisciplinar de Pesquisa e Extensão em Contemporaneidade, Imaginário e Teatralidade - GIPE-CIT na UFBA desde 1994. É coordenador do Grupo de Trabalho de Etnocenologia da Associaçáo Brasileira de Pesquisa e Pós-Graduação em Artes Cênicas ABRACE desde 2007.

${ }^{3}$ João de Jesus Paes Loureiro é poeta e professor de Estética, História da Arte e Cultura Amazônica, na Universidade Federal do Pará. É mestre em Teoria da Literatura e Semiótica da PUC/UNICAMP e doutor em Sociologia da Cultura pela Sorbonne, Paris, França.

${ }^{4}$ Artigo selecionado para comunicação no II ENGRUPEDANÇA - Diálogos e Dinâmicas, Encontro dos Grupos de Pesquisa em Dança, realizado pela Universidade Federal do Rio de Janeiro - UNIRIO e publicado em Mídia Digital em 2009.

\section{Referências}

BIÃO, Armindo Jorge de Carvalho. Etnocenologia e a Cena Baiana: textos reunidos, Salvador: P\&A Gráfica e Editora, 2009.

LOBATO, Lúcia Fernandes. Potenciais da Dança para uma Corpo-bio-grafia. Artigo selecionado para apresentação no II ENGRUPEDANÇA - Diálogos e Dinâmicas. Rio de Janeiro: Universidade Federal do Estado do Rio de Janeiro (UNIRIO), 2009. Publicado em mídia digital "CD-Textos" (ISSN n. 1982-2863).

LOUREIRO, João de Jesus Paes. A Conversão Semiótica, na Arte e na Cultura. Edição trilíngue. Belém: EDUFFPA, 2007.

MAFFESOLI, Michel. O Conhecimento Comum. São Paulo: Editora Brasiliense, 1988.

MAFFESOLI, Michel; LE MOIGNE, Jean-Louis. A Inteligência da Complexidade. São Paulo: Editora Fundação Peirópolis, 2000.

MORIN, Edgar. O Cinema ou o Homem Imaginário. Lisboa: Relógio D’Água Editores, 1997.

MORIN, Edgard; LE MOIGNE, Jean-Louis. A Inteligência da Complexidade. Petrópolis: Fundação Petrópolis, 2000.

MUNIZ, Fernando. Platão contra a Arte. In: HADDOCK-LOBO, Rafael (Org.). Os Filósofos e a Arte. Rio de Janeiro: Rocco, 2010. P. 20.

PRADIER, Jean-Marie. Ethnoscénologie, Manifeste. Théâtre-Public, Paris, n. 123, p. 46-48, maio/jun. 1995.

SANTOS, Milton. Por uma Geografia Nova. São Paulo: Hucitec, 1988.

VIANNA, Klauss. A Dança. São Paulo: Siciliano, 1990. 
Lúcia Fernandes Lobato é professora do Programa de Pós-Graduação em Artes Cênicas da Universidade Federal da Bahia e pesquisadora do Grupo Interdisciplinar de Pesquisa e Extensão em Contemporaneidade, Imaginário e Teatralidade - GIPE-CIT/ UFBA. Coordenadora do GT de Pesquisa em Dança no Brasil/ABRACE.

E-mail: lluciallobato@ig.com.br

Recebido em 22 de janeiro de 2013 Aprovado em 28 de abril de 2013 